Can Peer Assisted Learning be Effective in Undergraduate Mathematics?

Francis Duah, Tony Croft*, and Matthew Inglis

Mathematics Education Centre, Loughborough University, UK.

* Corresponding author: Email: a.c.croft@lboro.ac.uk 


\section{Can Peer Assisted Learning be Effective in Undergraduate}

\section{Mathematics?}

We report the implementation and evaluation of a 'peer assisted learning' (PAL) scheme designed to reduce the so-called "cooling off" phenomenon in undergraduate mathematics. "Cooling off" occurs when mathematics undergraduates lose motivation and interest in their studies, despite having previously actively chosen to study it at higher levels. We found that, despite concerns about the novel didactic contract inherent in PAL schemes, a majority of students chose to engage with the scheme, and that the student leaders of the PAL sessions were generally capable of implementing a student-centred pedagogy. Furthermore we found that students who attended the PAL sessions had higher achievement in their final examinations, even after controlling for their lecture attendance and prior attainment. We conclude by arguing that PAL may provide a useful mechanism for reducing the prevalence of the "cooling off" phenomenon in some - but not all - groups of mathematics students.

Keywords: undergraduate mathematics, cooling-off, peer-assisted learning 


\section{Introduction and background}

There is a growing body of literature that discusses the academic experiences of undergraduate mathematics students, and in particular the difficult transition between school and university-level study. Several researchers have described how the enthusiasm for mathematics with which students enter higher education is, for many, short-lived [e.g., 1-3]. Students of many disciplines find the transition to university study difficult, but it would appear that moving into, and through, single honours mathematics courses presents particular challenges. Our goal in this paper is to discuss and evaluate a peer assisted learning (PAL) scheme that was designed to address these issues in a cohort of second year mathematics undergraduates. We begin by describing the theoretical context in which the scheme was situated.

Several researchers have used the term "cooling off" to describe one possible outcome of students' encounters with university-level mathematics $[2,4]$. Students who “cool off" experience a transition from an initial enthusiasm with mathematics (and in particular, school-level mathematics) to disaffection and reduced achievement. Daskalogianni and Simpson [2] suggested that this transition is caused by a mismatch between the students' beliefs about the nature of mathematics and mathematics education, and the teaching and learning environment they experience at the university level [e.g., 5,6]. Others have reported similar findings: Goulding, Hatch \& Rodd [7] conducted a large survey of mathematics graduates, asking them about their experience of studying university mathematics. They found ample evidence of the "cooling off" phenomenon, and how, along with their academic achievement, it influences students' affective experiences. One student, for example, described their experience of studying mathematics by saying "I hated it most of the time... It became difficult to enjoy some of the maths modules if you were struggling and couldn't get any help" [7, p. 373]. 
Another reported that they had felt "isolated" and that this became more apparent in later years when the "difficulty level increased" [7, p. 373]. Many students commented upon the "shock" of discovering that not only the difficulty of the subject matter had substantially increased from school-level mathematics, but that there were fewer support mechanisms to which they could turn. Solomon [8] pointed out that many students choose to study mathematics at university precisely because they find it easy in school-level education. Given this, she argued, such students may rapidly lose motivation and "cool off" when the work becomes more difficult and success cannot be guaranteed.

While the step change in difficulty noted by Solomon [8] and others may occur immediately following the transition to university, Macrae, Brown, and Bartholomew [9] argued that it also often influences second year students. Croft and Grove [10] agreed, pointing out that because substantial efforts have been made to help students with the initial transition into university mathematics (notably the development of mathematics support centres), this causes problems for students tackling the transition from first year to second year studies. It is at this point when the mathematical material studied increases in sophistication, and when additional support aimed at first year students is typically no longer available.

The danger is that, if left unaddressed, students who are "cooling off" may eventually entirely disengage with their studies and eventually drop out $[2,11]$. Macrae, Brown and Bartholomew pointed out that it is difficult to develop pedagogical strategies to address this phenomenon:

"It is difficult to know what more the university could do to support these struggling students especially as they tend to withdraw when faced with lack of 
success and many find it difficult to talk openly and honestly about their situation." $[9$, p. 60].

Solomon [12] observed similar problems when she interviewed 12 first year undergraduate mathematicians at a different university with a "strong research culture". She found 'not-belonging' was a prevalent theme and whilst the students in her study were able mathematicians who were aligned with departmental practices and mathematical norms in terms of following systems of rules and practices, their selfdescriptions placed them as existing on the margins of practice. Solomon argued that "systems we do not own and cannot contribute to are no more than rule-bounded situations in which we participate only as rule followers...". These findings have strong resonance with groundwork undertaken for our own study wherein we found students who would go on to gain good degrees nevertheless reporting feelings of being outsiders who had little say in the diet (both in terms of mathematical content and pedagogy) they were being fed. Solomon went on to argue that "mathematics can only be made accessible to all in a participatory pedagogy which encourages exploration, negotiation and ownership of knowledge" (pp. 92-93). Our goal in this paper is to investigate the possibility of beginning to address this "cooling off" phenomenon by creating the kind of participatory pedagogy advocated by Solomon through the mechanism of Peer-Assisted Learning (PAL). As we shall see, PAL provided opportunities for students to start to take ownership of their learning in a way which was meaningful and helpful to them.

\section{Peer-assisted learning}

In recent years universities from a variety of countries have implemented peerassisted learning schemes [e.g., 13]. Although precise characteristics of each scheme vary, they all share similar properties. In this paper, we define peer-assisted learning 
(PAL) to be a formal scheme of assistance that is provided by one or more students to other students to enable them to develop their understanding of course content, and also to assist them develop the study skills required to be successful on the course. A critical feature of PAL is that it is discussion-based and run by students' peers: it therefore seems a promising method to adopt in undergraduate mathematics, given Solomon's [12] emphasis on participatory pedagogy and student ownership of knowledge.

PAL has been evaluated in a variety of studies and attendance at PAL sessions has been found to correlate with increased academic performance in disciplines including nursing [14], medicine [15-16], law [17], accounting [18-19], economics [20], English [13], microbiology [21], and chemistry [22-23]. Although some studies have focussed on the use of PAL in mathematics courses [23-30], these have been in the context of service courses (mathematics modules taught to non-specialists, such as engineering students). To the best of our knowledge, this paper is the first evaluative study that has investigated the use of PAL in an advanced mathematics course designed for specialist mathematicians, and particularly for students in their second year.

Indeed, there are particular reasons to question whether PAL would be as effective in a single honours advanced mathematics course as it has been demonstrated to be in other contexts, including service mathematics courses. As noted above, a key characteristic of the PAL approach is that it is based on peer-to-peer discussion. But as earlier researchers have noted, undergraduate mathematics is typically taught in a traditional fashion, sometimes characterised as "chalk and talk" lecturing [e.g., 31]. Once students have progressed beyond the transition year they have become extremely familiar with this pedagogy, and an implicit 'didactic contract' (a term used by Brousseau [32] to denote the 'rules of the game' in didactic situations) has become established [e.g., 33-34]. Thus to introduce a new (optional) discussion-based PAL 
activity into the second year of a mathematics programme which has, up until then, adopted only traditional pedagogies requires the renegotiation of the didactic contract. It is not certain that this renegotiation will be successful. And, if unsuccessful, it is plausible to suppose that many students would simply disengage with the novel pedagogy.

Our goal here then, is to ask whether PAL can be an effective pedagogic intervention within the second year of a traditional mathematics programme. Specifically, we report a study that evaluated a PAL programme designed to address the issue of "cooling off" in the second year mathematics undergraduate cohort at Loughborough University, a research intensive university in the midlands of England.

\section{Context of the study}

The School of Mathematics at Loughborough has a traditional UK three- or four-year undergraduate degree that emphasises rigorous proof-based mathematics from the first year. The PAL intervention was focused on a second year module on Vector Spaces, which traditionally students found to be one of the harder modules. Topics covered in the module included rings, modules, fields, vector spaces, subspaces, quotient spaces, linear maps, inner product spaces, the Cauchy-Schwarz inequality, and quadratic forms. The course consisted of three-hours of classes per week taught in a traditional fashion (similar to the style discussed by Weber [31]. Nominally, two of these hours were "lectures" and one was a "tutorial", although as discussed below, in practice the line between these two forms of teaching was somewhat blurred. The PAL intervention consisted of two distinct stages. The first stage was the recruitment and training of students who had completed successfully the module Vector Spaces in the academic year 2010/11. During their third year they would act as peer mentors, referred to during the project as 'student leaders'. In the second stage, Semester 1 of academic 
year 2011/12, all current second year students had the option of attending weekly 50 minute PAL sessions led by the student leaders.

In early summer 2011, an internal advertising campaign by poster and email drew the forthcoming PAL scheme to the attention of prospective student leaders. Whilst the student leaders would be unpaid, the personal benefits accruing through participation in the scheme were highlighted. These included academic benefits arising through reworking the second year module, but this time as PAL leaders. They were informed about the opportunities arising through training and development in key transferable skills such as communication, team working and leadership. In addition, the University operates an 'Employability Award' and participation as a student leader would earn a substantial number of credits. Two lunchtime sessions were used to provide more detail and give the prospective student leaders the opportunity to ask questions. Thirteen students (of the 92 eligible) attended and all signed up to become student leaders. There was no explicit selection of student leaders but, in fact, all had achieved a good result in Vector Spaces by the time that they took up their role. In July 2011, these thirteen volunteers were offered a half-day training led by staff from the University's central teaching support facility. This session provided an introduction to PAL and how it was expected to work. In particular, the principle that the role of the student leaders was one of facilitator of group learning rather than that of a mathematics tutor was emphasised.

In September 2011 a full day's training took place. On this occasion students were taught how to co-facilitate their PAL sessions, recognise key features of a successful PAL session, and reflect on successful and unsuccessful learning strategies. They began to explore the design of resources and activities to be used in their sessions. An important element of the training was the modelling of a PAL session. An 
experienced mathematics lecturer began by giving a mini-lecture to the student leaders and to two mathematics staff members. The material was designed to be unfamiliar to the audience. Thereafter, the two staff members played the role of student leaders, working with the group to draw out explanations of what the lecture had been about without actually tutoring themselves. Practical issues such as record keeping, accessing additional support and the importance of liaising with the module lecturer were discussed.

At the beginning of Semester 1, 2011/12 several student leaders attended the first of the Vector Spaces lectures. They briefly explained the PAL scheme and invited the 83 students registered for the module to sign up to attend PAL sessions. The module lecturer was extremely supportive of the scheme and encouraged students to sign up. 77 students signed up to one of five timetabled slots. In the event, 57 students accessed peer support at least once, with many being regular attenders (attendance data is analysed in detail below).

The PAL sessions were timetabled for weeks 1-5 and then 7-10 of Semester 1. Teaching rooms were provided for the PAL sessions. Breathing space was built into the schedule with no sessions in Week 6 so that the implementation team could take stock and review whether modifications were necessary. One of the five slots was disbanded due to lack of attendance; one of the two student leaders joined another slot, and the other moved peripatetically around the groups. The PAL sessions were entirely 'student-owned'. Whilst the module lecturer had provided additional material which could be covered in the sessions, no staff attended (other than a researcher who observed a sample of sessions), and what went on within the sessions was directed entirely by the student leaders and the second year students. 
To achieve our overarching research goal of understanding whether PAL might be a practical method of implementing Solomon's [12] recommendation that a participatory pedagogy be adopted to help address the "cooling off" phenomenon, we asked two main questions. First, can PAL run effectively in the context of a traditional undergraduate mathematics programme? Or does the novel didactic contract inherent in PAL cause students to disengage and become disaffected? Second, is it effective in terms of reducing the "cooling off" phenomenon? In particular, does attending PAL sessions raise students' mathematical achievement?

\section{Method}

In view of our two primary research questions, we adopted a mixed methods approach involving parallel [35] collection of qualitative and qualitative data. Eight PAL sessions (out of a total of 36) were observed, and field notes taken. The purpose of the observations [36] was to ascertain whether PAL sessions ran in line with the training provided for the PAL leaders. A training session, held prior to the start of the Vector Spaces course, was video recorded and analysed to identify the strategies that the PAL leaders were expected to use in facilitating PAL sessions. We also conducted five in depth semi-structured [36] interviews with students who attended some (or all) of the sessions. Several students who were approached for interviews declined to participate, and we also analysed the reasons they gave for this (where reasons were offered and consent to use them as data was given). The data gathered from the interviews were analysed thematically [36-37] in order to corroborate the observation data, and to gauge students' views on the effectiveness of the PAL sessions. Again, these interviews were audio recorded and transcribed for analysis. The interview data were coded to identify descriptive categories [38] which were then grouped into common themes. One of the 
themes pertinent to this paper is $P A L$ sessions and learning environment which will be discussed in the next section.

To address the second question, we collected a range of quantitative data. We monitored students' attendance at (a) PAL sessions (registers were kept by student leaders) and (b) a randomly chosen sample of 6 of the 22 traditional lectures (students were asked to swipe their library cards as they entered the lecture theatre; this was enforced by a team of research assistants). We monitored the lecture attendance in order to provide a baseline measure of academic engagement. In addition we obtained students' prior academic achievement in a first year linear algebra module (the prerequisite for the Vector Spaces module) and end-of-module Vector Spaces examination and coursework performance from the university's records (the module was assessed by $90 \%$ final closed book examination, and $10 \%$ a "class test", an informal examination taken during lecture periods).

\section{Can PAL sessions run in the context of undergraduate mathematics?}

In this section we report the typical features of how the PAL sessions were run by the student leaders. From the field notes taken during the observations of PAL sessions and interviews with PAL participants, we were able to surmise that the PAL sessions ran well, and for the most part, had features that reflect the kind of participatory pedagogy suggested by Solomon [12].

In a typical PAL session, we noted that PAL leaders would welcome students to the session and announce the topic for discussion in the session. Topics for discussion in a session were normally collected by the PAL leaders in advance by email. Conversation with some PAL participants and PAL leaders during an observation revealed that one PAL group, on their own initiative, created a Facebook group through which suggestions of topics for discussion were solicited or put forward by the PAL 
participants of that group. In some sessions observed, the PAL leaders decided on topics for discussion after ascertaining from the PAL participants the part of the Vector Spaces lecture notes on which the lecturer and the participants have been working. The PAL leaders showed evidence of preparation for all sessions observed, albeit with flexibility to incorporate participants' requests.

PAL leaders often gave the PAL participants a starter activity to complete. For example, Interviewee 1 described how a typical session would begin:

"We always start with a sort of icebreaker question, just to get everyone thinking about the topic that was being covered in the lectures at that time."

The starter activity often involved the PAL participants working in pairs or groups of three or four. Some of these activities were created by the team of academics that introduced and championed the PAL initiative; others were created by the PAL leaders themselves. An example of a starter activity which was used in PAL sessions during one week is shown in Figure 1. The second part of this activity generated both group and whole class discussions. Interviewee 2 recounted how such discussions typically occurred:

"They ... asked us to provide the steps necessary to complete the question and generate the correct answer. We threw ideas out and they told us if they thought those steps were correct or whether we needed to have a rethink about how we were approaching the problem. Then once we as a group agreed and knew what we were doing, they put the corresponding steps on the board, so that we could all copy it down."

In the sessions observed, we noted that PAL leaders encouraged active participation in discussions during the sessions using rewards in the form of prizes (e.g. 
sweets) and this often yielded active discussion amongst PAL participants. As sessions developed, leaders employed a range of strategies to get the PAL participants involved.

When PAL participants asked questions, the PAL leaders often redirected questions back to them; but there were some occasions when the fine line between session facilitation and provision of answers to questions was blurred. The PAL leaders typically moved around the PAL participants in their sessions, but at times could also been seen facilitating from the front of the classroom. For example, Interviewee 4 described some of the strategies used by PAL leaders in a typical session:

“They'll get you into groups and stuff. It's not fixed that you'll be put with the same people, but it's just a different set of people. Then, you'll be given some problems and you have to work together in the group to obtain the answers, then you'll demonstrate the answers to other people in your group and you can be challenged by other groups if they don't obtain the same answer and then ask why they got that and how it differs from your answers. And then just ask them about general problems that you're having or material that you don't understand, as well."

The development of sessions beyond the starter activity often involved the discussion of "problem sheets" assigned by the course lecturer for tutorials, tests items or past exam papers. This often constituted a significant part of the sessions observed. PAL leaders were observed splitting up and rephrasing lecture notes, with the aim of enabling the students to improve their comprehension. Alongside such techniques, the PAL leaders typically asked questions and checked for students' understanding. For example, a section of a chapter of the Vector Spaces lecture notes focused on the Spectral Theorem and some students reported that they found this topic difficult. In one 
of the observed sessions, the PAL leaders discussed and paraphrased the notes on the Spectral Theorem on a board, as shown in Figure 2.

When asked to compare and contrast the way PAL sessions and traditional tutorials for Vector Spaces are run, Interviewee 3 gave the following response:

"The tutorials are more formal than the student leader sessions. That's because the tutorials still feel somewhat like a lecture with more examples than a lecture, for sure. But very structured, in that the lecturer or the postgrad students will be up at the front explaining how to do something or watching us to make sure we know what we're doing and we're doing it. But there's less opportunity for conferring and generally sharing ideas."

PAL leaders seemed to know the names of the PAL participants in their groups and used participants' names to encourage active participation in sessions. It seemed clear that, for the most part, the PAL leaders were successful in building rapport with the students which enabled them to share their own experiences of studying the module. For example, PAL leaders were observed discussing, with PAL participants, parts of the Vector Spaces lecture notes that they felt were important for examination purposes. PAL leaders were also observed providing re-assurance to PAL participants. For example, a PAL leader was heard telling a group of PAL participants that despite the difficulty they could be having with the course, in the end they would succeed in their examination.

When ending sessions, often PAL leaders typically did not provide a plenary which summarised the concepts discussed, and neither did they ask the PAL participants to summarise the session themselves. Instead, they typically thanked the students for their participation and encouraged them to attend the next session. We noted, from 
comments made by some PAL participants and PAL leaders, that the latter also encouraged PAL attendance via e-mail and Facebook.

Despite observing generally successful sessions, we also found evidence that our concerns about introducing a novel form of pedagogy which broke the didactical contract was not entirely misplaced. One student, when declining to be interviewed, explained that she had decided not to attend sessions because she preferred the traditional pedagogy favoured by some lecturers, to the discursive pedagogy implemented by student leaders:

"To be honest I found the tutorials from some lecturers are more useful than the PAL group, because the lecturers would teach us how to do the questions together properly and give us time to do so; whereas I went to the PAL group sessions twice [and] the leaders give us some tasks to do with a partner or on your own [which] made it seem like a competition with the others."

Similar comments were made by some other students. One explained:

"I think [the PAL sessions] could have been improved by being led by the third year students more instead of us sitting around doing our own work and them helping. I would have preferred to have listened to their explanations of the week's topics."

In summary, the evidence from our observations of the PAL sessions and from the interviews with five of the PAL participants suggested that those students who attended the sessions mostly found them to be useful, and adapted well to the novel discussion-based pedagogy. Nevertheless, there was some evidence that some students objected to the new pedagogy, and would have preferred if the PAL sessions had been 
run in a more traditional format with student leaders playing the role of a lecturer explaining material to them directly.

\section{Session attendance and achievement}

The second of our research questions concerned the relationship between attending PAL sessions and student achievement. Although this is a causal question, for ethical reasons we were not able to conduct a true experiment (with students randomly allocated into two groups: those who were permitted to attend PAL sessions and those who were not); given this, our analysis is correlational only. Nevertheless, we attempted to control for key factors which might covary with PAL attendance and mathematical achievement. Specifically, earlier research has demonstrated that higher lecture attendance is associated with higher achievement in undergraduate mathematics [39]. Similarly, we expected that student achievement on a first year linear algebra module would be strongly correlated with achievement on the Vector Spaces module in which the PAL intervention took place (the content of the Vector Spaces module built heavily on the earlier linear algebra module). Consequently, we used these two factors as covariates in our analysis.

Descriptive statistics concerning PAL session attendance, lecture attendance, linear algebra achievement and Vector Spaces achievement are shown in Table 1. The mean number of PAL sessions (out of a maximum of 9) attended by students registered on the Vector Spaces module was 3.80 ( $\mathrm{SD}=3.48)$, with $31 \%$ of students opting to not attend any sessions. Of those students who did attend at least one session, the mean attendance was $5.53(\mathrm{SD}=2.84)$.

The zeroth order correlations between the four variables of interest are given in Table 2. There was a significant correlation between PAL attendance and Vector Spaces achievement, $r=.426, p<.001$. However, as expected, both prior attainment in the first 
year linear algebra module and lecture attendance in Vector Spaces predicted students' Vector Spaces module mark. Consequently we calculated the partial correlation between PAL attendance and Vector Spaces achievement, controlling for linear algebra achievement and Vector Spaces lecture attendance, finding a significant positive relationship, $p r=.243, p=.034$. This relationship is shown in Figure 3. In other words, if two students had attended the same number of lectures, and had started the module with identical prior achievement, then the student with the higher PAL attendance typically achieved higher end of year module marks.

To investigate the size of the PAL effect, we ran a multiple regression analysis, predicting students' Vector Spaces achievement using PAL attendance, lecture attendance and linear algebra achievement. The regression coefficient associated with PAL attendance was $b=1.182$, indicating that each additional PAL session attended was associated with around $1.2 \%$ extra in the final module assessment. If this relationship were causal, we would expect students who attended each of the nine sessions to gain over $10 \%$ in the final assessment, enough to raise marks by an entire degree class (in the UK undergraduate degrees are graded in 10\% bins).

\section{Replication study}

In view of the apparent success of the PAL scheme in the Vector Spaces module, it was decided to run the PAL intervention for a separate module in the semester following the Vector Spaces module. In order to provide some degree of replication for our earlier findings, we again collected quantitative (but not qualitative) data concerning student attendance and attainment. The target second semester module was Complex Variables, a module which had again traditionally seen high failure rates and low lecture attendance (an indication of the cooling off phenomenon). A total of 
127 students were registered on the module, and the PAL sessions were organised and ran in a similar fashion to those for the Vector Spaces module.

As before we recorded the number of times each student attended a sample of six of the timetabled lectures associated with the module, the number of times they attended PAL sessions, and we obtained each students' mark on the first year module Geometry, Vectors and Complex Numbers (GVCN, a prerequisite for the Complex Variables module) as well as their final mark on the target Complex Variables module.

The analysis proceeded in a similar fashion to that reported earlier. Again we found that first year GVCN marks, $r=.524, p<.001$, and complex variables lecture attendance, $r=.272, p=.002$, correlated with Complex Variables attainment, so we used these variables as covariates in our primary analysis. When we correlated PAL attendance with Complex Variables attainment, controlling for first year GVCN marks and lecture attendance, we found a significant positive correlation, $p r=.196, p=.030$. In the multiple regression, the coefficient associated with PAL attendance was of a similar size to that found in the first semester, $b=1.116$. This indicated that, on average, every one additional PAL session attended was associated with an additional $1.1 \%$ on the final module marks.

In summary, the quantitative data collected in the second semester (with a different module, (some) different students and (some) different PAL leaders), showed an essentially identical pattern of results to that found in the first semester.

\section{Discussion}

Our goal in this paper was to investigate whether peer assisted learning might be an appropriate tool to address the well-known "cooling off" phenomenon observed in the context of undergraduate mathematics courses. Earlier researchers have noted that the "cooling off" of students who were previously enthusiastic about mathematics is 
both serious and hard to solve $[2,11]$. Solomon [12] suggested that a fruitful method of addressing this issue would be to move away from traditional undergraduate teaching methods [e.g., 31] and develop a participatory pedagogic approach. In this paper we investigated whether PAL might be an appropriate way of implementing Solomon's [12] suggestion. Although PAL has been shown to be effective in non-mathematical domains, we are aware of no previous research which has investigated whether it can be successfully used in single honours mathematics courses, the context in which "cooling off' has been observed, and particularly in the second year.

We asked two main questions. First, is it possible to successfully incorporate PAL into an undergraduate mathematics degree (with a traditional didactic contract)? Second, is PAL effective at increasing students' attainment, and therefore reducing the "cooling off" phenomenon noticed by earlier researchers?

With respect to the first question, we found that the PAL sessions appeared to run relatively smoothly. PAL sessions seemed to be informal and welcoming for students, and involved discussion of mathematics topics which had previously been suggested by the PAL participants. Sessions typically involved paired, small or whole group discussions of a short opening activity followed by discussion of difficult parts of lecture notes, problem sheets, tests and examination items.

With reference to our second question - whether PAL was effective at increasing students' attainment - we found a positive relationship between students' PAL attendance and their final module mark, even after controlling for prior attainment and lecture attendance (and this relationship was also found in a subsequent replication study). Although we cannot rule out the possibility of some unknown confounding factor accounting for this relationship (note that any such confound would have to be uncorrelated with both prior attainment and lecture attendance), we believe that this 
finding is sufficiently encouraging to call for further research into the effectiveness of PAL in undergraduate mathematics.

One important limitation to our analysis is that we operationalised the "cooling off" phenomenon by considering student attainment only. Although earlier researchers have proposed that the phenomenon is characterised by a lack of students' success [e.g. $8,11]$, it is also characterised by a lack of enthusiasm and general reduction in engagement with academic mathematics. It would be extremely valuable if, in future, investigations which study interventions designed to address the "cooling off" phenomenon could find strategies to measure affective aspects such as enthusiasm and engagement. Of course, it is particularly difficult to effectively collect such data from students who have actively disengaged with their studies (which was one of the reasons we concentrated our analysis on attainment data), but such data is critical if the "cooling off" phenomenon is to be understood from all angles.

Although our overall conclusions are positive, we also found evidence that PAL does not offer a total solution to "cooling off". Most notably, around a third of the cohort on the module chose not to attend any PAL sessions at all. Although the sessions were not compulsory, this figure is sufficiently large to suggest that PAL on its own is not a complete solution to the "cooling off" phenomenon observed by earlier researchers. Our qualitative evidence suggested that some students at least decided not to attend because they did not appreciate the discursive pedagogy, and that they would rather have had additional presentations of the material in a traditional lecture format. These results therefore call into question Solomon's [12, p. 92] suggestion that mathematics "can only be made accessible to all in a participatory pedagogy" (our emphasis): we found examples of students who actively chose to disengage with such 
an approach, and who claimed to prefer the more traditional didactic pedagogical style found in lectures.

Our findings therefore are consistent with Macrae et al.'s [9] observation that designing pedagogy to reduce the "cooling off" phenomenon is challenging. Nevertheless, we believe that the results of our evaluation demonstrate that, for a large number of students, PAL has the potential to raise engagement with and achievement in second year undergraduate mathematics. Designing pedagogical interventions which reach students who opt not to engage in the type of discursive pedagogy favoured by Solomon [12] and others is an important challenge which would be valuable for future research to address.

\section{Acknowledgements}

We are grateful to the HE STEM Programme for funding for this initiative as part of a wider curriculum development project. The role of mathematics staff and students as well as staff from the University's Teaching Centre who contributed to the training and implementation of the PAL scheme is also gratefully acknowledged.

\section{References}

[1] H. Bartholomew and M. Rodd, A fiercely held modesty: the experiences of women studying mathematics. New Zealand Journal of Mathematics, 32 (2003), pp. 9-13.

[2] K. Daskalogianni and A. Simpson, "Cooling-off": The phenomenon of a problematic transition from school to university. Proceedings of the Second International Conference on the Teaching of Mathematics at the Undergraduate Level. Crete, Greece, 2002. 
[3] Y. Solomon, D. Lawson, and T. Croft, Dealing with 'fragile identities': resistance and refiguring in women mathematics students. Gender and Education, 23 (2011), pp. $565-583$.

[4] B. Cooper, PGCE students and investigational approaches in secondary maths. Research Papers in Education, 5, (1990), pp.127-151.

[5] A. Robert, and R. Schwarzenberger, (1991). Research in Teaching and Learning Mathematics at an Advanced Level. In D. Tall (Ed.), Advanced Mathematical Thinking, pp. 127-139. Dordrecht: Kluwer Academic Publishers, 1991.

[6] D. Tall, Reflections on Advanced Mathematical Thinking. In D. Tall (Ed.), Advanced Mathematical Thinking, pp. 251-259. Dordrecht: Kluwer Academic Publishers 1991.

[7] M. Goulding, G. Hatch, and M. Rodd (2003). Undergraduate mathematics experience: Its significance in secondary mathematics teacher preparation. Journal of Mathematics Teacher Education, 6,(2003) pp. 361-393.

[8] Y. Solomon, Mathematical literacy: Developing identities of inclusion. Routledge, Abingdon, UK, 2009.

[9] S. Macrae, M. Brown, and H. Bartholomew, The tale of the tail: An investigation of failing single honours mathematics students in one university. In J. Williams (Ed.), Proceedings of the British Society for Research into Learning Mathematics (Vol. 23, pp. 55-60). Oxford: BSRLM. 2003

[10] T. Croft and M. Grove, Mathematics support: Support for the specialist mathematician and the more able student. MSOR Connections, 6,(2006), pp. 1-5. [11] B. R. Clark, The "cooling out" function in higher education. The American Journal of Sociology, 65 (1960), pp. 569-576. 
[12] Y. Solomon, Not belonging? What makes a functional learner identity in undergraduate mathematics? Studies in Higher Education, 32 (2007), pp. 79-96. [13] E. Longfellow, S. May, L. Burke, and D. Marks-Maran, 'They had a way of helping that actually helped': a case study of a peer-assisted learning scheme. Teaching in Higher Education, 13 (2008), pp. 93-105.

[14] M. Harding. Efficacy of supplemental instruction to enhance student success. Teaching and Learning in Nursing, 7 (2012), 27-31.

[15] J. P. Forester, P. P. Thomas, P. P. and D. L. McWhorter. Effects of four supplemental instruction programs on students' learning of gross anatomy. Clinical Anatomy, 17 (2004), pp. 322-327.

[16] L.G. Glynn, A. MacFarlane, M. Kelly, P. Cantillon, and A. W. Murphy, Helping each other to learn - a process evaluation of peer assisted learning. BMC Medical Education, 6 (2006), Retrieved from http://www.biomedcentral.com/content/pdf/14726920-6-18.pdf

[17] M. Donelan, and P. Kay (1998). Supplemental instruction: Students helping students' learning at University College London (UCL) and University of Central Lancashire (UCLAN). The Law Teacher, 32 (1998), pp. 287-299.

[18] M. Dobbie and S. Joyce, Peer-assisted learning in accounting: A qualitative assessment. Asian Social Science, 4 (2008), pp. 18-25.

[19] M. Dobbie, M. and S. Joyce, Does peer-assisted learning improve student marks in accounting? Asian Social Science, 5 (2009), pp. 3-9.

[20] A. Worthington, J. Hansen, J. Nightingale, and K. Vine, Supplemental instruction in introductory economics: An evaluation of the University of New England's peer assisted study scheme, Australian Economic Papers, (1997) pp. 69-80. 
[21]] V. N. Tariq, Introduction and evaluation of peer-assisted learning in first-year undergraduate bioscience, Bioscience Education E-Journal, 6. (2005) Retrieved from http://www.bioscience.heacademy.ac.uk/journal/vol6/beej-6-3.pdf

[22] E. M. Coe, A. McDougall and N. B. McKeown, Is peer-assisted learning of benefit to undergraduate chemists? University Chemistry Education, 3 (1999), pp. $72-$ 75.

[23] M. Parkinson, The effect of peer assisted learning support (PALS) on performance in mathematics and chemistry. Innovations in Education and Teaching International, 46 (2009), pp. 381-392.

[24] S.L. Burmeister, P. A. Kenney, A. McLaren and D. L. Nice, Analysis of effectiveness of supplemental instruction (SI) sessions for college algebra, calculus, and statistics. In J. Kaput, A. H. Schoenfeld \& E. Dubinsky (Eds.), Research in Collegiate Mathematics Education, II (Issues in Mathematics Education Vol 6, pp.145-155). Providence, RI: American Mathematical Society, 1996.

[25] D. Cheng and M. Walters, Peer-assisted learning in mathematics: An observational study of student success, Journal of Peer Learning, 2, (2009) pp. 23-39. [26] J. Condell, and P. Yogarajah, Evaluation of peer assisted learning in mathematics (PALM) for second-year undergraduate mathematics. Journal in Teaching and Learning - Perspectives on Pedagogy and Practice, 1 (2010), pp. 71-83.

[27] V. Fayowski and P. D. MacMillan, An evaluation of the supplemental instruction programme in a first year calculus course. International Journal of Mathematical Education in Science and Technology, 39 (2008) pp. 843-855.

[28] A. Harding, J. Engelbrecht and A. Verwey, Implementing supplemental instruction for a large group in mathematics. International Journal of Mathematical Education in Science and Technology, 42 (2011) pp. 847-856. 
[29] P. A. Kenney and J. M. Kallison, Research studies on the effectiveness of supplemental instruction in mathematics. New Directions for Teaching and Learning, 60 (1994), pp. 75-82.

[30] J. Malm, L. Bryngfors and L. Morner, Supplemental instruction for improving first year results in engineering studies, Studies in Higher Education (iFirst). (2011) doi: $10.1080 / 03075079.2010 .535610$

[31] K. Weber, Traditional instruction in advanced mathematics courses: A case study of one professor's lectures and proofs in an introductory real analysis course. The Journal of Mathematical Behavior, 23 (2004) pp. 115-133.

[32] G. Brousseau, Theory of didactical situations in mathematics (edited and translated by N. Balacheff, M. Cooper, R. Sutherland \& V. Warfield). Dordrecht, Netherlands: Kluwer, 1997.

[33] L. Alcock, and A. Simpson, The Warwick Analysis project: Practice and theory. In D. Holton (ed.), The Teaching and Learning of Mathematics at University Level (pp. 99-111). Dordrecht, Kluwer, 2001.

[34] P. W. Thompson, Students, functions, and the undergraduate curriculum. In E. Dubinsky, A. H. Schoenfeld, \& J. J. Kaput (Eds.), Research in Collegiate Mathematics Education, 1 (Issues in Mathematics Education Vol. 4, pp. 21-44). Providence, RI: American Mathematical Society, 1994.

[35] R. B. Johnson and A. J. Onwuegbuzie, Mixed Methods Research: A Research Paradigm Whose Time Has Come. Educational Researcher, 33 (14) (2004) 14-26. [36] A. Bryman, Social Research Methods. Oxford: Oxford University Press, 2008. [37] V. Braun, and V. Clarke, (2006). Using thematic analysis in qualitative research in psychology, Qualitative Research in Psychology, 3 (2006), pp. 77-101. 
[38] J. W. Creswell, Qualitative Inquiry and Research design: Choosing among five approaches. Thousand Oaks, LA:Sage, 2013.

[39] M. Inglis, A. Palipana, S. Trenholm, and J. Ward, Individual differences in students' use of optional learning resources. Journal of Computer Assisted Learning, 27(2011), 490-502. 
Tables

Table 1. Descriptive statistics for the four variables of interest.

\begin{tabular}{lcccc}
\hline & Mean & SD & Min & Max \\
\hline PAL session attendance & 3.80 & 3.48 & 0 & 9 \\
Lecture attendance & 4.29 & 1.67 & 0 & 6 \\
Linear Algebra achievement & 64.7 & 14.36 & 37.0 & 96.0 \\
Vector Spaces achievement & 55.7 & 20.01 & 2.0 & 97.0 \\
\hline
\end{tabular}


Table 2. The zeroth order correlations between our four variables of interest. $\dagger p$ $<.1, * * p<.01, * * * p<.001$.

\begin{tabular}{lcccc}
\hline & 1 & 2 & 3 & 4 \\
\hline 1. PAL session attendance & - & $.524^{* * *}$ & $.286^{* *}$ & $.426^{* * *}$ \\
2. Lecture attendance & & - & $.216^{\dagger}$ & $.346^{* *}$ \\
3. Linear Algebra achievement & & - & $.643^{* * *}$ \\
4. Vector Spaces achievement & & & - \\
\hline
\end{tabular}




\title{
Figures
}

Figure 1. An example of a starter activity produced for a PAL session.

\author{
Vector Spaces
}

\section{Eigenvalues}

\section{Part I}

Which of the following is equivalent to $\lambda \in K$ being an eigenvalue of the linear map $L: V \rightarrow V$ ?

(a) $\operatorname{ker}(L-\lambda \cdot$ id $)=\emptyset$

(b) $\operatorname{ker}(L-\lambda \cdot$ id $) \neq \emptyset$

(c) $\operatorname{ker}(L-\lambda \cdot$ id $)=\{0\}$

(d) $\operatorname{ker}(L-\lambda \cdot$ id $) \neq\{0\}$

(e) $(L-\lambda \cdot$ id $)$ is injective

(f) $(L-\lambda \cdot$ id $)$ is not injective

(g) There is a $v \in V$ such that

$$
(L-\lambda \cdot \mathrm{id}) v=0
$$

(h) There exists a non-zero $v \in V$ such that

$$
L v=\lambda \cdot v
$$

(i) For every $v \in V$ we have

$$
L v=\lambda \cdot v
$$

\section{Part II}

Discuss if, for an $n \times n$-matrix $A$, the following two statements are equivalent:

(a) $A-\lambda \cdot$ id is invertible.

(b) $\lambda$ is not an eigenvalue. 
Figure 2. An example showing how PAL leaders used the board to rephrase lecture notes on the Spectral Theorem.

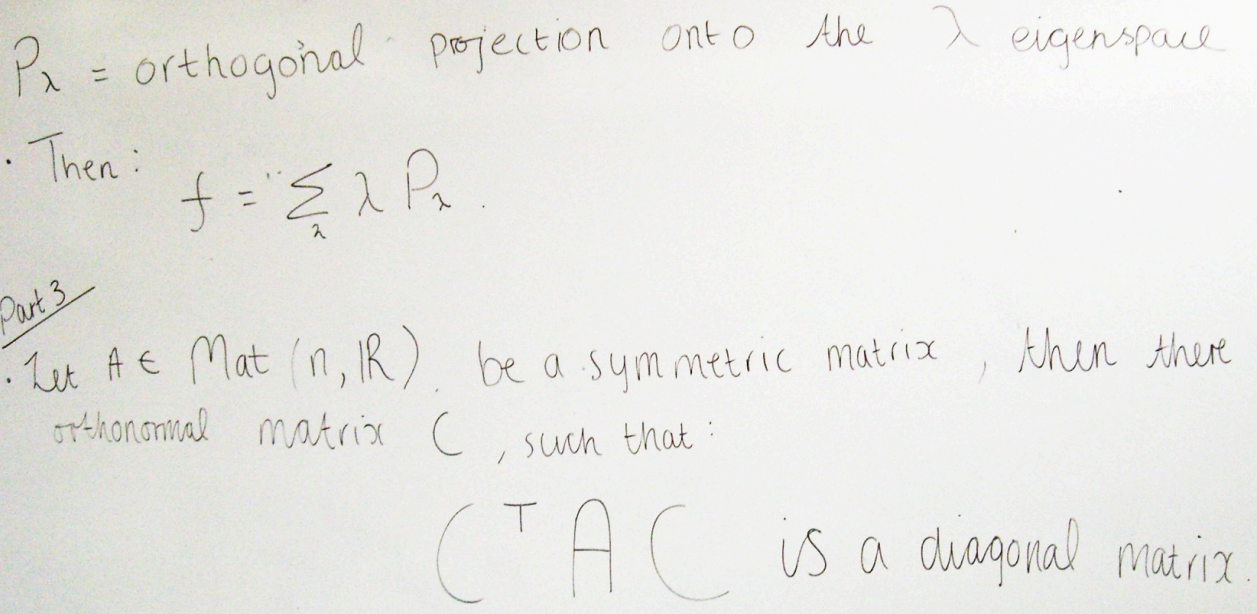


Figure 3. The relationship between PAL attendance and Vector Spaces achievement, controlling for prior attainment and lecture attendance (the points plotted are the standardised residuals when each component was regressed against linear algebra achievement and Vector Spaces lecture attendance).

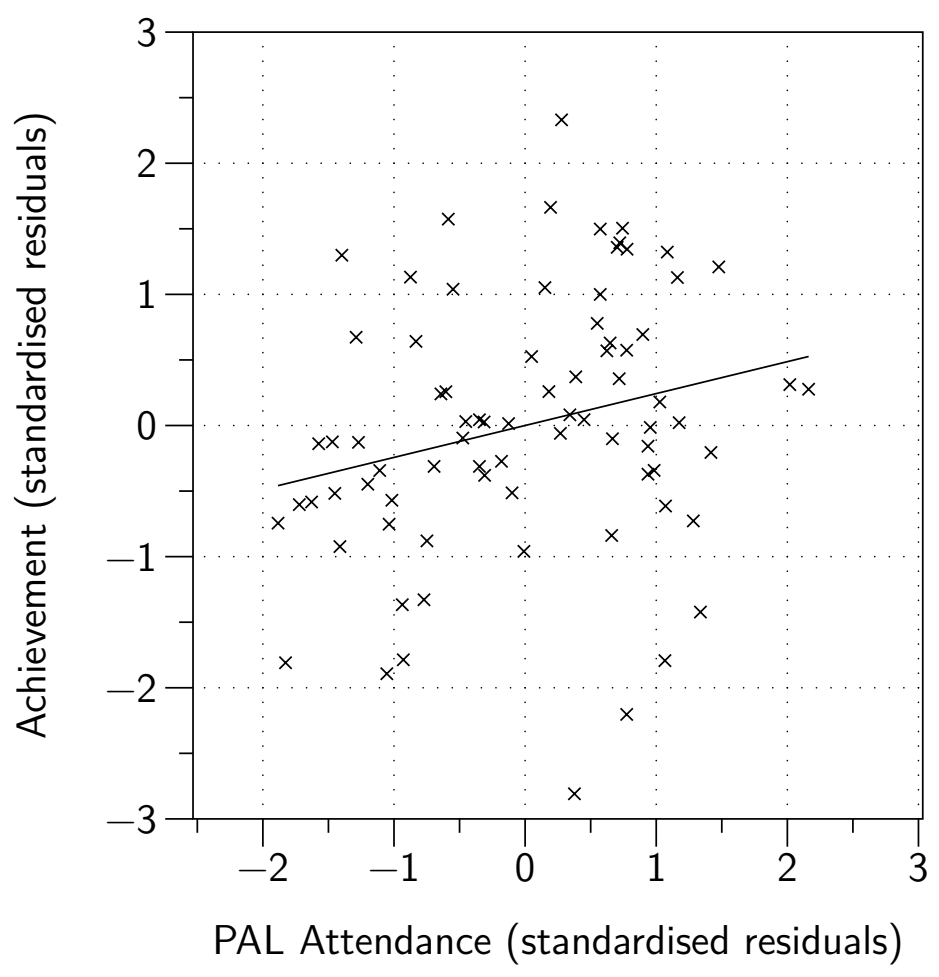

